\title{
Intoxicação por Ramaria flavo-brunnescens (Clavariaceae) em bovinos ${ }^{1}$
}

\author{
Ricardo R. Barros ${ }^{2}$, Luiz F. Irigoyen ${ }^{3}$, Glaucia D. Kommers ${ }^{3}$, Raquel R. Rech ${ }^{2}$, \\ Rafael A. Fighera ${ }^{2}$ e Claudio S.L. Barros ${ }^{3 "}$
}

\begin{abstract}
Barros R.R., Irigoyen L.F., Kommers G.D., Rech R.R., Fighera R.A. \& Barros C.S.L. 2006. [Poisoning by Ramaria flavo-brunnescens (Clavariaceae) in cattle.] Intoxicação por Ramaria flavo-brunnescens (Clavariaceae) em bovinos. Pesquisa Veterinária Brasileira 26(2):87-96. Departamento de Patologia, Universidade Federal de Santa Maria, 97105-900 Santa Maria, RS, Brazil. E-mail: claudioslbarros@uol.com.br

Two oubreaks of poisoning by the mushroom Ramaria flavo-brunnescens are reported in cattle from two farms located in the municipalities of Santa Maria and São Gabriel, state of Rio Grande do Sul, during April-May 2005. Out of a total of 180 yearling calves that had access to a pasture with eucalyptus woods, 19 were affected and 10 died. The clinical courses were 8-15 days and clinical signs included depression, weight loss, dehydration, drooling, loosening and loss of the long hairs of the tip of the tail, smoothening of the dorsal surface of the tongue with occasional ulceration, loosening of the corneal encasement of horns, hard and ball-shaped feces covered with a film of mucous, hypopion, hyphema and corneal opacity. Two calves had leucocytosis due to mild regenerative left shift. Nine calves were necropsied. Necropsy findings confirmed the clinical observation and additionaly included fibrinonecrotic esophagitis, mainly in the distal third of the esophageal mucosa. Histopathological changes in the skin of the tail included orthokeratotic hyperkeratosis; hair folicles with irregular contours, thickening of the tricolemmal keratin layer with occasional formation of keratin plugs, and degeneration and necrosis of the outer root sheath. At the laminar region of the hooves, there was hyperplasia of the top of epidermal laminae with irregular keratinization and retention of nuclei; several epidermal laminae were shortened and fused. There was hemorrhage, fibrin and neutrophilic infiltrate in the dermal laminae. In the mucosa of the tongue there was thinning of the covering epithelium, atrophy and loss of filiform papillae, multifocal areas of dyskeratosis, and spongiosis of the basal cell layer. In some parts the epithelium was lost and the surface consisted of granulation tissue and mixed inflammatory cell infiltrate. The esophageal mucosae of six calves had varying degree of epithelial necrosis and inflammation. The loss of the covering epithelium revealed an underneath area of granulation tissue with heavy inflammatory infiltrate composed predominantly of neutrophils and macrophages. In six calves there were focal symmetric bilateral areas of malacia observed at the level of obex in the medulla oblongata and affecting the white matter and parts of the dorsal nucleus of the vagus and of the hypoglossal nucleus. The epidemiology, clinical signs, pathology, and pathogenesis of poisoning by $R$. flavo-brunnescens in cattle are discussed.
\end{abstract}

INDEX TERMS: Poisonous plants, Ramaria flavo-brunnescens, Clavariaceae, plant poisoning, mushroom poisoning, keratinization defect, focal symmetric encephalomalacia, diseases of cattle, pathology.

\footnotetext{
${ }^{1}$ Recebido em 11 de novembro de 2005.

Aceito para publicação em 28 de novembro de 2005.

Parte da Dissertação de Mestrado do primeiro autor:

2 Programa de Pós-Graduação em Medicina Veterinária, área de concentração em Patologia Veterinária, Centro de Ciências Rurais, Universidade Federal de Santa Maria (UFSM).

${ }^{3}$ Depto Patologia, UFSM, 97105-900, Santa Maria, Rio Grande do Sul. *Autor para correspondência. E-mail: claudioslbarros@uol.com.br
}

RESUMO.- Dois surtos de intoxicação pelo cogumelo Ramaria flavo-brunnescens são relatados em bovinos de duas fazendas localizadas nos municípios de Santa Maria e São Gabriel, no Rio Grande do Sul, no período de abril-maio de 2005. De um total de 180 bovinos de sobreano que tiveram acesso a bosques de eucaliptos, 19 adoeceram e 10 morreram. A evolução clínica foi de 8-15 dias e os sinais clínicos incluíam depressão, perda de 
peso, desidratação, salivação excessiva, afrouxamento e perda dos pêlos longos da cauda, alisamento da superfície dorsal da língua com ocasional ulceração, afrouxamento do estojo córneo dos chifres, fezes em forma de cíbalos e recobertas por película de muco, hipópion, hifema e opacidade da córnea. Dois novilhos tinham leucocitose devido a leve desvio regenerativo à esquerda. Os achados de necropsia confirmaram as observações clínicas e adicionalmente incluíam esofagite fibrinonecrótica, principalmente no terço distal do esôfago. Alterações histopatológicas na pele da cauda incluíam hiperqueratose ortoqueratótica, folículos pilosos com contornos irregulares, espessamento da camada de queratina tricolemal e formação ocasional de tampões de queratina; degeneração e necrose da bainha radicular externa também era observada. Nos cascos havia hemorragia, fibrina e infiltrado neutrofilico nas lâminas dérmicas, hiperplasia do topo das lâminas epidérmicas com queratinização irregular e retenção dos núcleos; várias lâminas epidérmicas estavam encurtadas e fundidas. Na mucosa da língua o epitélio de revestimento estava adelgaçado, com atrofia e perda das papilas filiformes, áreas multifocais de disqueratose e espongiose das células da camada basal. Em algumas porções havia perda do epitélio e a superfície da língua era formada por tecido de granulação e infiltrado inflamatório misto. A mucosa esofágica de seis novilhos apresentava vários graus de necrose epitelial e inflamação. A perda do epitélio de revestimento revelava uma área subjacente de tecido de granulação com marcado infiltrado inflamatório predominantemente neutrofilico e macrofágico. Em seis novilhos, o bulbo, na altura do óbex, apresentava áreas focais bilaterais e simétricas de malacia que afetava a substância branca e partes do núcleo dorsal do vago e do núcleo hipoglosso. São discutidos a epidemiologia, os sinais clínicos, a patologia e a patogênese da intoxicação por R. flavo-brunnescens em bovinos.

TERMOS DE INDEXAÇÃO: Plantas tóxicas, Ramaria flavo-brunnescens, Clavariaceae, intoxicação por planta, intoxicação por cogumelo, distúrbio da queratinização, encefalomalacia focal simétrica, doenças de bovinos, patologia.

\section{INTRODUÇ̃̃O}

O cogumelo Ramaria flavo-brunnescens, da família Clavariaceae, cresce exclusivamente em solos de matas de eucaliptos (Fidalgo \& Fidalgo 1970), é palatável e sua ingestão espontânea tem causado intoxicação em bovinos (Bauer et al. 1966, Santos et al. 1975, Paschoal et al. 1983, Kommers \& Santos 1995), ovinos (Prucoli \& Camargo 1965/66, Riet-Correa et al. 1983, 2004) e, menos freqüientemente, búfalos (Rozza et al. 2004) e eqüinos (Santos et al. 1975, 1993), das regiões Sul e Sudeste do Brasil. A intoxicação é também registrada em bovinos no Uruguai (Freitas et al. 1966, Quinõnes-Sowerby 1973) e Argentina (Zurbriggen et al. 1985). Devido a consistente associação entre a toxicose e o pastoreio em matas de eucalipto a doença foi denominada "mal do eucalipto”. No Uruguai, o acrônimo bocopa foi empregado para designar a doença em razão das lesões ocorrerem na boca, cola e patas (Freitas et al. 1966). O mal do eucalipto tem ocorrência sazonal definida que coincide com o ciclo de vida do cogumelo (fevereiro-junho) que é especialmente abundante em outonos quentes e chuvosos após verões secos (Paschoal et al. 1983, Tokarnia et al. 2000).
Desde o primeiro relato da doença em bovinos (Barros 1958), a intoxicação tem sido reproduzida em bovinos (Bauer \& Laranja 1966, Santos et al.1975, Zurbriggen et al. 1985, Kommers \& Santos 1995) e ovinos (Prucoli \& Camargo 1965/66, Sallis et al. 2000, 2004).

Os aspectos clínicos e patológicos da doença em bovinos incluem depressão, anorexia, salivação excessiva, alisamento da superfície dorsal da língua, afrouxamento e perda dos pêlos da vassoura da cauda, afrouxamento e perda da porção córnea dos cascos e chifres, opacidade da córnea, hemorragia da câmara anterior do olho e ulcerações focais ou multifocais na língua e esôfago (Santos et al.1975, Kommers \& Santos 1995, Riet-Correa et al. 2004). O curso clínico varia de 8-30 dias, após os quais os bovinos afetados morrem ou se recuperam (Santos et al.1975, Kommers \& Santos 1995).

Este trabalho descreve os aspectos epidemiológicos, clínicos e anatomopatológicos de dois surtos espontâneos da intoxicação por R. flavo-brunnescens, incluindo a descrição de malacia focal simétrica no tronco encefálico, lesão que não tinha ainda sido associada à essa intoxicação.

\section{MATERIAL E MÉTODOS}

Os dados epidemiológicos e clínicos da intoxicação pelo cogumelo Ramaria flavo-brunnescens (Atk.) Corner foram obtidos através de visitas às propriedades onde ocorreram os surtos, designadas Propriedades A e B. Duas visitas foram realizadas na Propriedade A e uma visita na Propriedade B. Os dados foram complementados por questionários aplicados aos proprietários e veterinários que atenderam aos surtos. Seis bovinos (Bov. 1-6) e três bovinos (Bov. 7-9) foram necropsiados pelos autores respectivamente nas Propriedades A e B. Hemogramas foram realizados em quatro bovinos (Bov. 2, 4-6) da Propriedade A. Dos nove bovinos necropsiados, oito foram submetidos à eutanásia quando moribundos e um deles (Bov. 7) teve morte espontânea. De todos os bovinos necropsiados, foram colhidos para histopatologia fragmentos dos seguintes órgãos: abomaso, casco (dígito do membro torácico direito), coração, encéfalo, esôfago, fígado, globo ocular, língua, omaso, pele (corte transversal da ponta da cauda), pulmão, retículo, rim e rúmen. Foi colhido também um conjunto de tecidos que incluía a rete mirabile carotídea, os gânglios do nervo trigêmeo e a hipófise. Três regiões da língua foram amostradas: ápice, corpo e raiz. Cada um dos nove encéfalos colhidos foi fixado inteiro em 6 litros de formol a $10 \%$, por duas semanas. De cada caso, os seguintes fragmentos do encéfalo foram selecionados para exame histológico após a fixação: (1) bulbo na altura do óbex, (2) cerebelo, (3) ponte com pedúnculos cerebelares, (4) mesencéfalo na altura dos colículos rostrais (5), diencéfalo através da massa intermédia e (6) lobo frontal na altura do joelho do corpo caloso e dos núcleos da base. Os fragmentos de encéfalo e dos outros tecidos foram processados rotineiramente para histologia e corados pela hematoxilina e eosina (HE).

Os índices de precipitação pluviométrica mensal no Rio Grande do Sul, desde janeiro de 2002 até setembro de 2005, foram obtidos junto à Estação Climatológica do Departamento de Fitotecnia do Centro de Ciências Rurais da Universidade Federal de Santa Maria.

\section{RESULTADOS}

\section{Epidemiologia}

As Propriedades A e B são localizadas respectivamente nos municípios de Santa Maria e São Gabriel, no Rio Grande do Sul. 


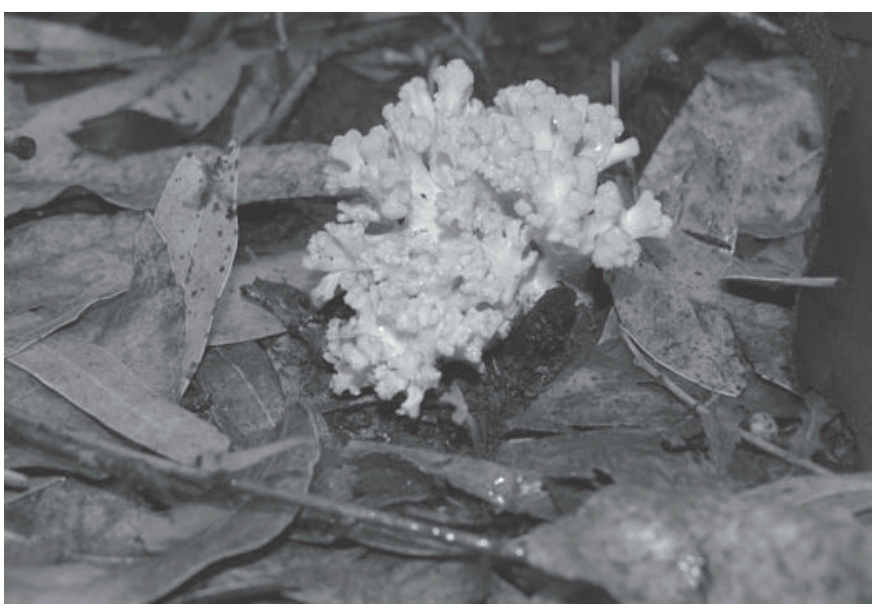

Fig.1. Espécime do cogumelo Ramaria flavo-brunnescens que era abundante no solo das matas de eucalipto das duas propriedades onde ocorreram os surtos da intoxicação. O cogumelo é algo semelhante a uma couve-flor, amarelo-alaranjado e tem o ciclo de vida entre fevereiro e junho. Foto tomada em maio de 2005 na Propriedade B.

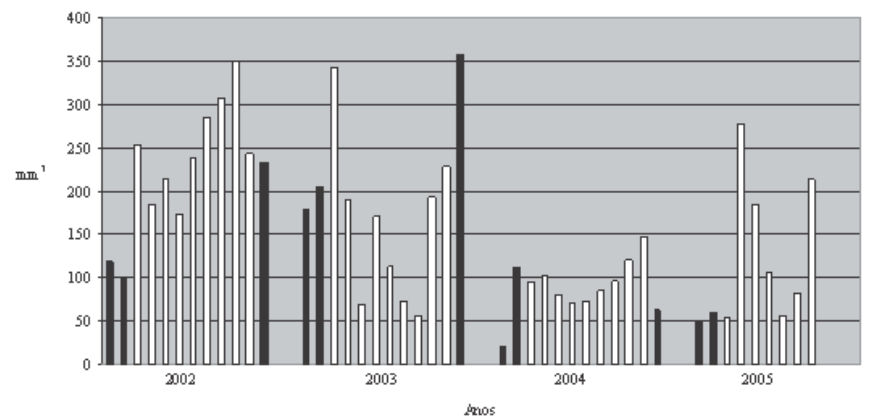

Fig.2. Índices de precipitação pluviométrica mensal no Rio Grande do Sul. Dados tomados de janeiro de 2002 a setembro de 2005. As barras pretas representam os meses de verão (dezembro-fevereiro). Observe que no verão de 2004/05 houve uma forte estiagem seguida de elevada precipitação pluviométrica nos meses de abril e maio, quando ocorreram os surtos de intoxicação por Ramaria flavo-brunnescens em bovinos. (Fonte: Estação Climatológica, Depto Fitotecnia do Centro de Ciências Rurais, Universidade Federal de Santa Maria)

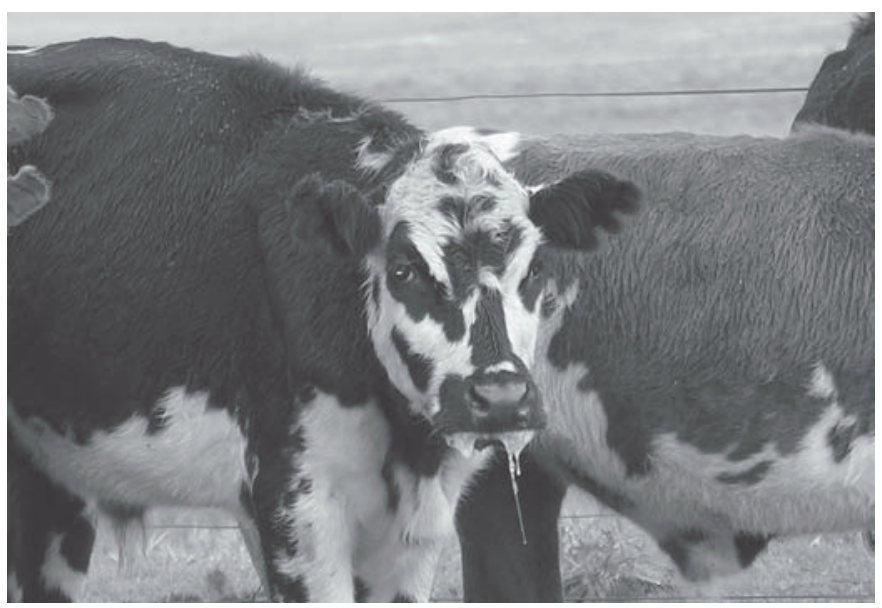

Fig.3. Animal com sialorréia, na intoxicação por Ramaria flavobrunnescens (Bovino 8).
Na Propriedade A, 24 novilhos de 18 meses estavam num potreiro de 20 hectares, dos quais 15 eram de mata de eucalipto. Os novilhos começaram a adoecer em 15 de abril. Até meados de maio de 2005, 12 novilhos haviam adoecido, 6 deles foram eutanasiados quando moribundos e 6 se recuperaram. Na Propriedade $B, 156$ novilhos de 18 meses estavam num pasto de 200 hectares, dos quais 40 eram de mata de eucalipto. Entre 18 de abril e 10 de maio de 2005, 7 novilhos adoeceram e 4 morreram. Em ambas as propriedades as matas de eucalipto eram infestados por abundante quantidade de Ramaria flavo-brunnescens (Fig.1). Os índices de precipitação pluviométrica mensal no Rio Grande do Sul, desde janeiro de 2002 até setembro de 2005 constam da Fig. 2 .

\section{Sinais clínicos}

Todos os bovinos afetados estavam em mau estado nutricional, enquadrando-se no Grau 1 na classificação de estado corporal adotada (Stöber et al. 1990). A doença apresentou uma evolução clínica de 8-15 dias. Sinais clínicos observados em todos os novilhos afetados incluíam depressão, emagrecimento, desidratação, salivação abundante (Fig. 3), afrouxamento e queda dos pêlos longos da vassoura da cauda (Fig.4) e alisamento da superfície dorsal da língua que, em 5 casos, mostrava úlcera arredondada de $2-4 \mathrm{~cm}$ de diâmetro na superfície dorsal do ápice. Sinais clínicos encontrados em apenas alguns dos novilhos afetados incluíam afrouxamento da porção córnea dos chifres (Fig.5), fezes em forma de cíbalos e recobertas por película de muco, hipópion, hifema e opacidade da córnea.

\section{Achados hematológicos}

Os Bovinos 2 e 5 apresentaram leucocitose, que variou de 16.000 a 22.100 leucócitos $/ \mathrm{mm}^{3}$ de sangue. Nesses dois novilhos a leucocitose resultou de um leve aumento na quantidade de neutrófilos segmentados (5.120 e $12.155 / \mathrm{mm}^{3}$ de sangue) e bastonetes (640 e $2.210 / \mathrm{mm}^{3}$ de sangue), isto é, desvio regenerativo à esquerda. No Bovino 2 , além do desvio, havia monocitose leve $\left(1.105 / \mathrm{mm}^{3}\right.$ de sangue).

\section{Achados de necropsia}

Todos os 9 bovinos necropsiados estavam em mau estado nutricional e havia desidratação do cadáver que variava de moderada (Bov.5 e 6) a acentuada (Bov.1-4, 7 e 9). Nos Bovinos 1, 3 e 6 havia formação de crostas no focinho com desprendimento focal do epitélio. Uma lesão característica e comum a todos os novilhos afetados era a perda dos pêlos longos da extremidade da cauda. Em 6 novilhos (Bov.1, 3, 5, 6, 8 e 9), a perda de pêlos era total e nos outros dois bovinos a perda era parcial, mas os pêlos remanescentes eram facilmente destacáveis. Em todos os bovinos era notável o alisamento da superfície dorsal da língua, em razão da atrofia das papilas filiformes (Fig.6); essas alterações eram acompanhadas, em 4 casos, por desprendimento do epitélio lingual que era recoberto por fibrina (Bov.1, 6, 7 e 9). Em 5 novilhos (Bov. 2-6) havia papilomas aleatoriamente distribuídos na pele da face; alguns deles, principalmente os localizados nas comissuras labiais do lado direito, apresentavam miíase. Em 3 casos (Bov.1, 5 e 6) percebeu-se um tom amarelado na pele da região interna do pavilhão auditivo e no esmalte dos dentes. 

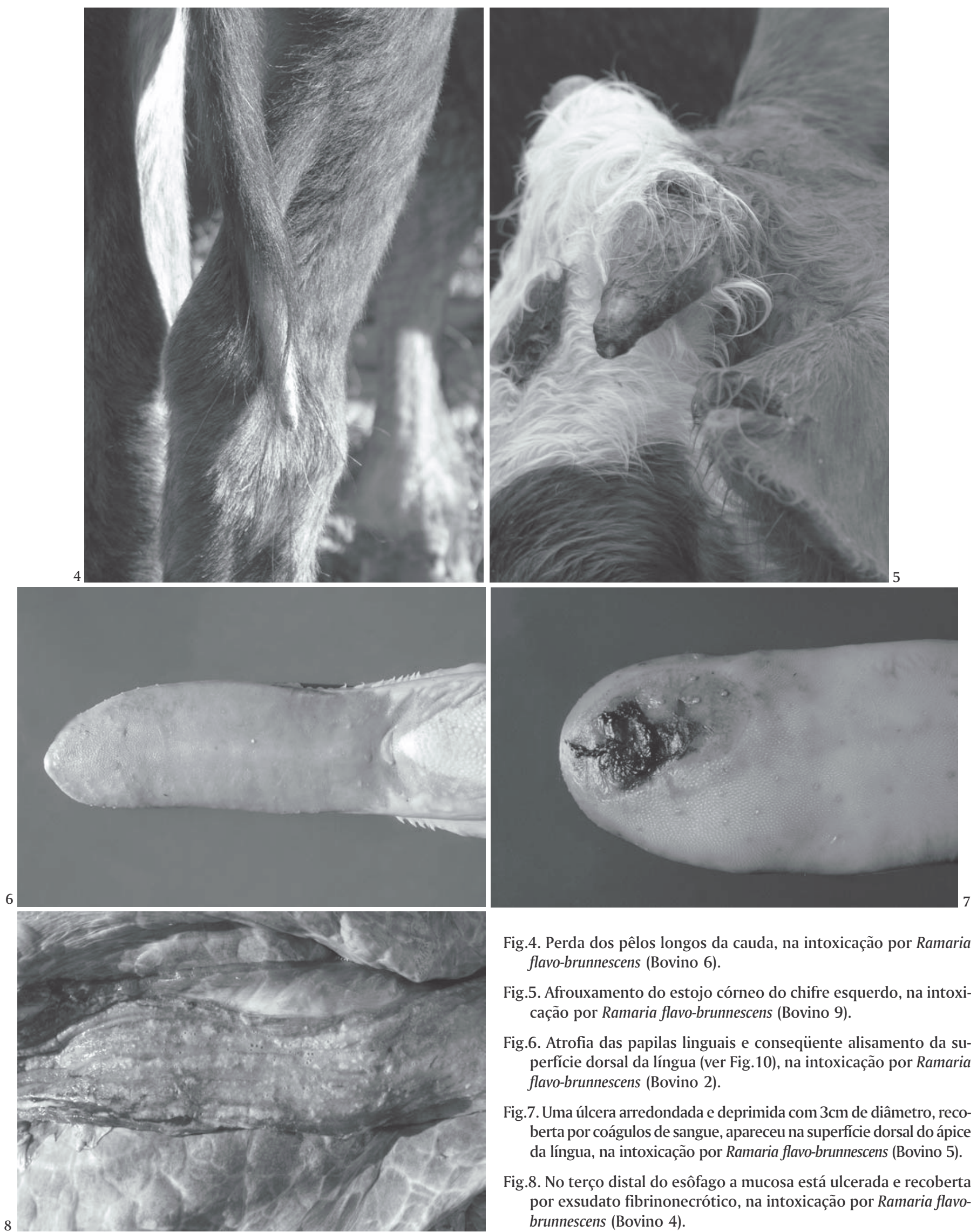

Fig.4. Perda dos pêlos longos da cauda, na intoxicação por Ramaria flavo-brunnescens (Bovino 6).

Fig.5. Afrouxamento do estojo córneo do chifre esquerdo, na intoxicação por Ramaria flavo-brunnescens (Bovino 9).

Fig.6. Atrofia das papilas linguais e conseqüiente alisamento da superfície dorsal da língua (ver Fig.10), na intoxicação por Ramaria flavo-brunnescens (Bovino 2).

Fig.7. Uma úlcera arredondada e deprimida com $3 \mathrm{~cm}$ de diâmetro, recoberta por coágulos de sangue, apareceu na superfície dorsal do ápice da língua, na intoxicação por Ramaria flavo-brunnescens (Bovino 5).

Fig.8. No terço distal do esôfago a mucosa está ulcerada e recoberta por exsudato fibrinonecrótico, na intoxicação por Ramaria flavobrunnescens (Bovino 4). 
A
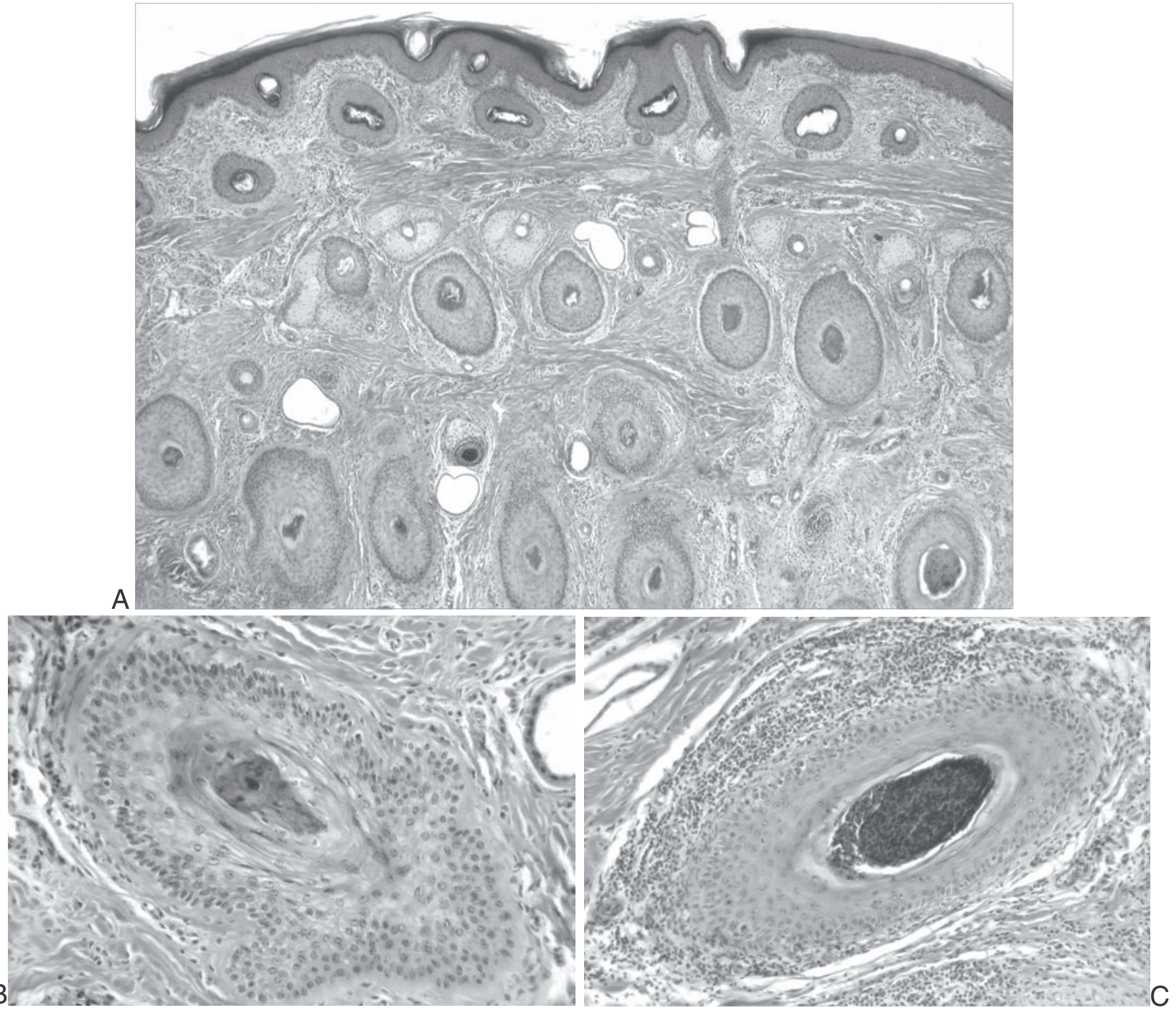

Fig.9. Histopatologia da pele da extremidade da cauda do Bovino 9, intoxicado por Ramaria flavo-brunnescens. (A) Moderada hiperqueratose ortoqueratótica. Os folículos pilosos apresentam espessa camada de queratina tricolemal, formando tampões de queratina. HE, obj. 20. (B) Folículo piloso da derme superficial em fase telogênica com contorno irregular e espessamento da bainha radicular fibrosa. HE, obj. 40. (C) Na luz folicular há detritos necróticos associados à queratina; ao redor do folículo piloso há infiltrado mononuclear composto por linfócitos e macrófagos. HE, obj. 40.

Em 5 dos novilhos necropsiados (Bov.2, 3, 5, 6 e 8) havia uma úlcera arredondada e deprimida, com diâmetros que variavam de $2-4 \mathrm{~cm}$, localizada na superfície dorsal do ápice da língua. No Bovino 5, a úlcera era recoberta por coágulos de sangue (Fig.7) e no Bovino 6 por fibrina. Mesmo nos outros bovinos em que essas úlceras não ocorriam, o epitélio da área correspondente à localização das úlceras era mais delgado. No Bovino 4 havia múltiplas úlceras bilaterais na região lateroventral da língua; nesse caso, as úlceras eram parcialmente cicatrizadas pois tinham os bordos espessos e salientes.

O esôfago dos Bovinos 6, 8 e 9 era normal, mas nos demais 6 bovinos havia erosões ou ulcerações lineares que podiam atin- gir toda a extensão da mucosa (Bov.1 e 2), mas, que, em todos os bovinos, poupavam os primeiros $30 \mathrm{~cm}$ da extensão da mucosa e eram mais pronunciadas no seu terço final. Na porção proximal do esôfago as erosões tinham aproximadamente $0,5 \mathrm{~cm}$ de diâmetro e eram semelhantes às que ocorrem em casos de infecção pelo vírus da diarréia viral bovina (BVD). No terço final, as lesões tinham caráter fibrinonecrótico e estavam recobertas por material escuro ou branco-esverdeado e eram semelhantes às da esofagite fibrinonecrótica que se observa em casos de uremia em bovinos (Fig.8). Nos Bovinos 5 e 7 havia edema respectivamente moderado e acentuado da mucosa do esôfago. A mucosa do abomaso dos Bovinos 4 e 5 estava acentuadamente avermelha- 


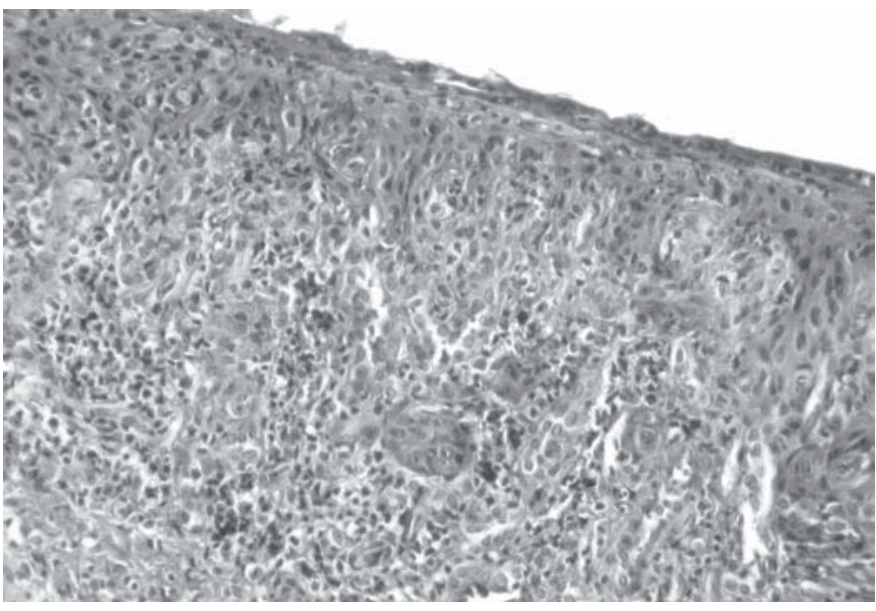

Fig.10. Histopatologia da língua do Bovino 4, intoxicado por Ramaria flavo-brunnescens. O epitélio está mais delgado que o normal e há desaparecimento (atrofia) das papilas filiformes. Na lâmina própria se observa tecido de granulação imaturo, infiltrado por neutrófilos, macrófagos, linfócitos e plasmócitos e incontinência pigmentar. HE, obj. 40. da e havia úlceras de $0,4 \mathrm{~cm}$ de diâmetro na porção fúndica da mucosa do abomaso do Bovino 5 .

Afrouxamento do estojo córneo dos chifres estava presente em dois casos (Bov.4 e 9). Nos Bovinos 2 e 5 fluía abundante quantidade de líquido cefalorraquidiano à abertura do crânio e as leptomeninges do encéfalo estavam moderadamente hiperêmicas. Em ambos os globos oculares dos Bovinos 2 e 9 respectivamente havia sangue (hifema) e exsudato branco opaco (hipópion) na câmara anterior do olho.

\section{Achados histopatológicos}

Na pele da ponta da cauda as lesões eram qualitativamente as mesmas em todos os bovinos, com algum grau de variação da intensidade das lesões entre eles. Na epiderme havia hiperqueratose ortoqueratótica moderada ou acentuada e os folículos pilosos da derme superficial apresentavam espessa camada de queratina tricolemal, formando tampões queratínicos e os vasos sangüíneos estavam íntegros (Fig.9A); somente em raros folículos observavase a haste do pêlo e grande número deles tinham o contorno irregular. Nos folículos da derme profunda havia intensa vacuolização, degeneração e necrose, principalmente da bainha

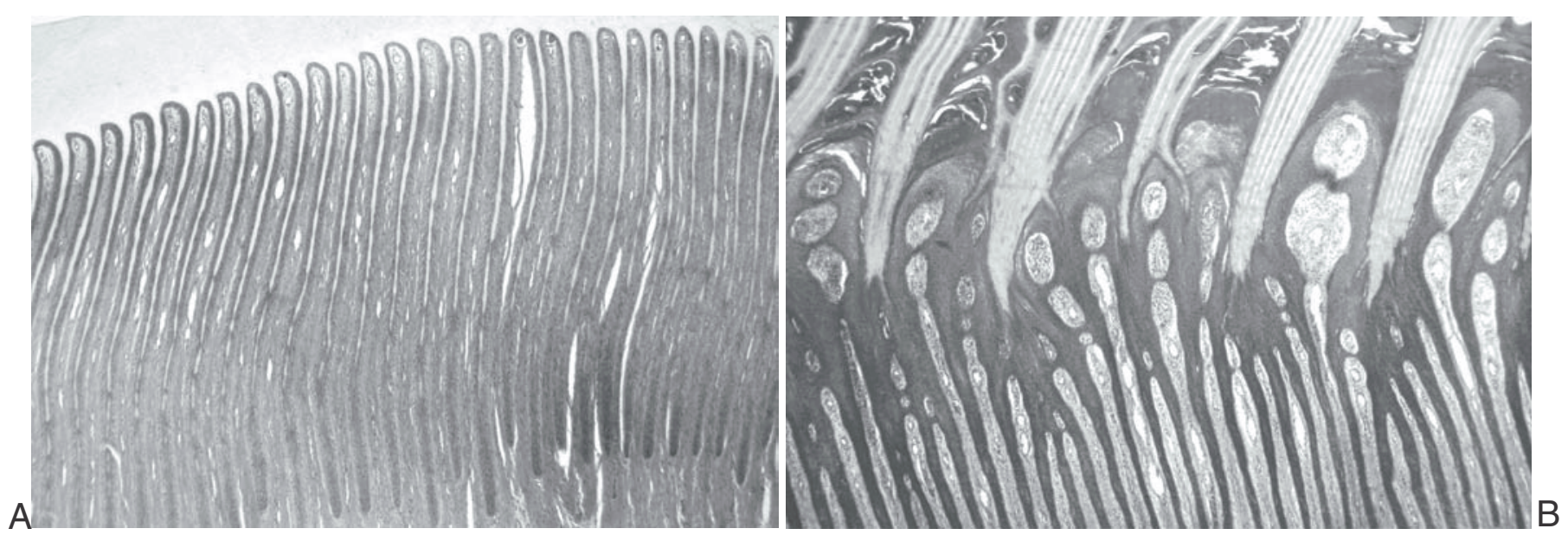

Fig.11. (A) Aspecto histológico normal do casco de bovino. (B) Na intoxicação por Ramaria flavo-brunnescens, várias lâminas epidérmicas estão encurtadas com fusão distal de queratina laminar irregular (flocular), apresentando hiperplasia epitelial e ausência de formação abrupta de queratina no interior das lâminas (Bovino 6). HE, obj. 20.

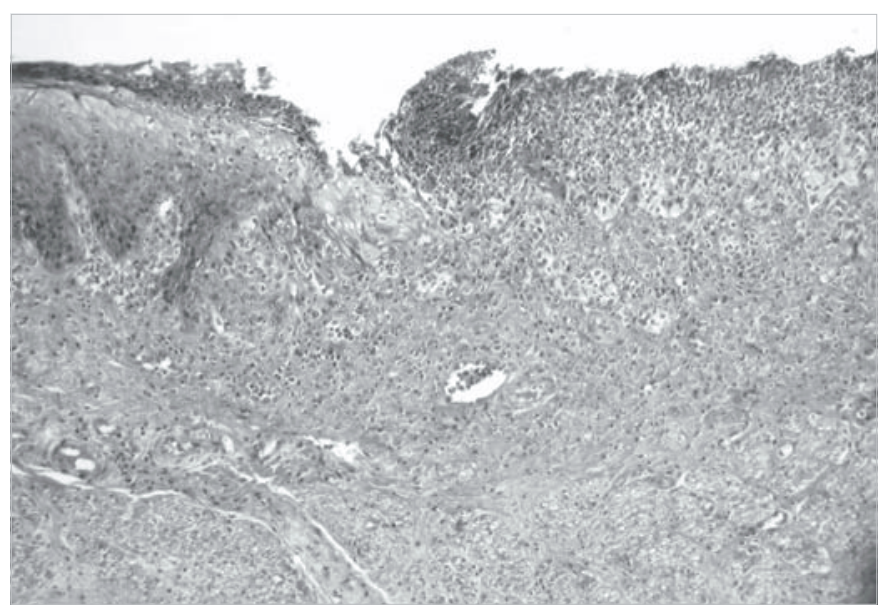

radicular externa (BRE), com algumas células em apoptose e alguns folículos apresentavam tampões queratínicos ou acúmulos irregulares de queratina tricolemal. Alguns folículos estavam fechados e com a bainha radicular fibrosa espessada, características de folículos em fase telogênica (Fig.9B). No interior de alguns folículos pilosos havia hastes de pêlo degeneradas com intensa pigmentação de melanina que se espalhava pela BRE degenerada. Na luz folicular havia detritos necróticos e neutrófilos associados à incontinência pigmentar. Em alguns casos observava-se leve

Fig.12. Histopatologia do esôfago do Bovino 2, intoxicado por Ramaria flavo-brunnescens. À esquerda, mucosa íntegra de esôfago. À direita, área focalmente extensa de perda total do epitélio com exposição de lâmina própria substituída por tecido de granulação infiltrado predominantemente por neutrófilos e macrófagos HE, obj. 20. 
hemorragia na papila dérmica. Entre os folículos pilosos mais afetados, havia infiltrado mononuclear multifocal composto por linfócitos e macrófagos (Fig.9C).

Nas seções do ápice, corpo e raiz da língua as lesões eram essencialmente iguais; havia adelgaçamento (atrofia) do epitélio de revestimento, atrofia com desaparecimento das papilas filiformes, áreas multifocais de disqueratose e áreas de espongiose da camada de células basais. No ápice da superfície dorsal da língua dos Bovinos 2, 3, 5, 6 e 8, o adelgaçamento do epitélio era contínuo com área ulcerada que se estendia até a
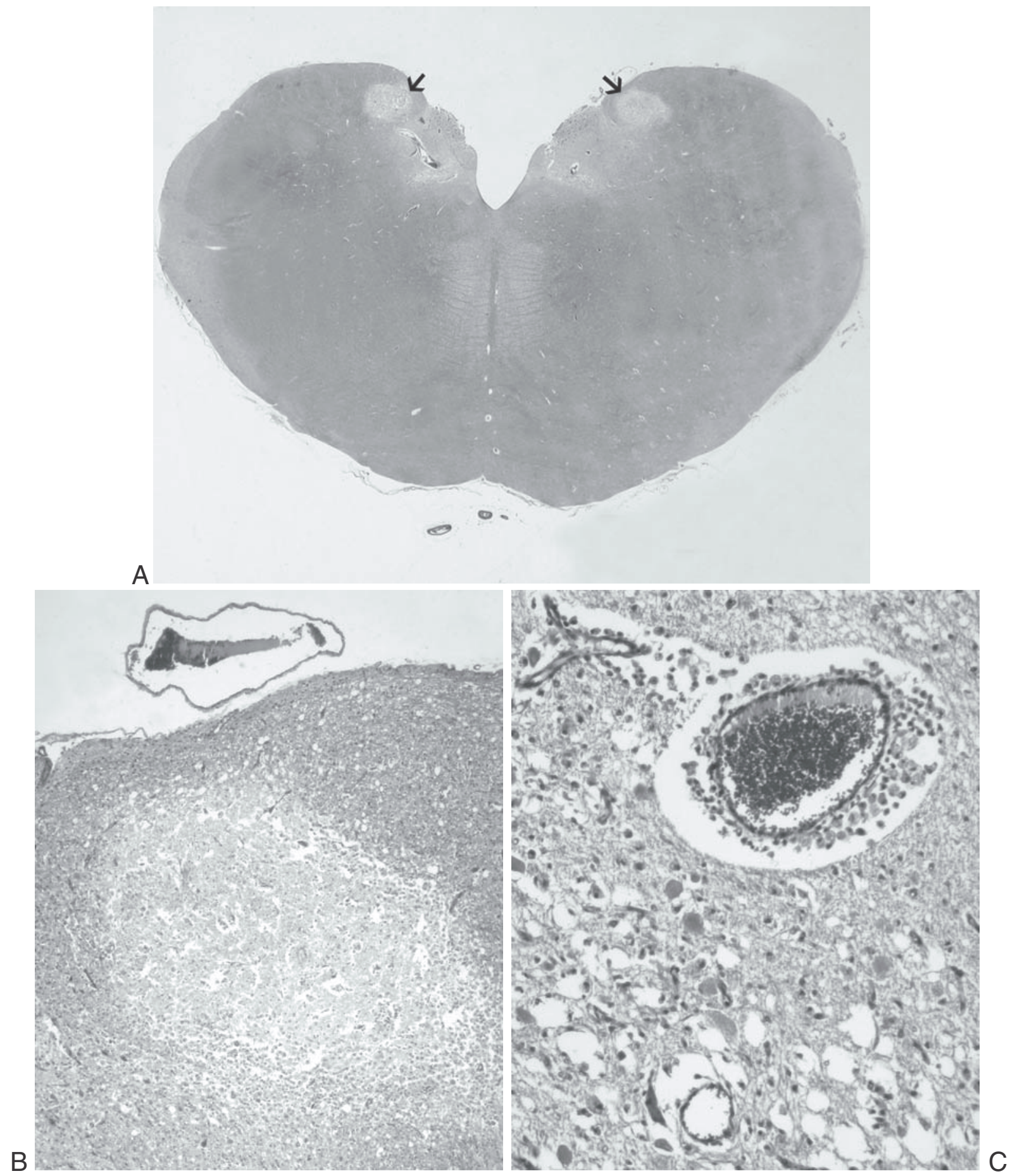

Fig.13. (A) Bulbo na altura do óbex, na intoxicação por Ramaria flavo-brunnescens (Bovino 2). Aspecto submacroscópico mostrando duas áreas focais simétricas de malacia (setas). HE, obj. 2,5. (B) Maior aumento da área de malacia mostrada em A. HE, obj. 20. Detalhe: borda da lesão mostrando acúmulo de células Gitter. HE, obj. 40. (C) Rarefação do núcleo dorsal do vago com degeneração neuronal e edema. Há um manguito de células Gitter em vaso na parte central superior da foto. Neste caso, o espaço perivascular atua como vaso linfático drenando os macrófagos espumosos (células Gitter) que contêm detritos fagocitados do foco de necrose. HE, obj. 40. 
lâmina própria, onde havia tecido de granulação imaturo infiltrado por neutrófilos, macrófagos, linfócitos e plasmócitos. $\mathrm{O}$ infiltrado inflamatório na lâmina própria do ápice da língua do Bovino 5 incluía ainda eosinófilos e células gigantes que cercavam fibras vegetais. Nos Bovinos 4 e 6 observou-se incontinência pigmentar na lâmina própria (Fig.10).

Em cinco novilhos (Bovinos 1-5) não foram observadas alterações histológicas na região laminar do casco. No Bovino 7 observava-se degeneração, hemorragia, fibrina e infiltrado neutrofílico nas lâminas dérmicas (córion laminar). No Bovino 8 havia hiperplasia leve no topo das lâminas epidérmicas com queratinização irregular e permanência dos núcleos. Havia hiperplasia epitelial multifocal leve no topo das lâminas epidérmicas no casco do Bovino 9 e no casco do Bovino 6, várias lâminas epidérmicas estavam encurtadas com fusão distal de queratina laminar irregular (flocular) (Fig.11). Nessa área, as lâminas epidérmicas apresentavam hiperplasia epitelial com vacuolização associada a queratina irregular e persistência de núcleos. Havia ausência de formação abrupta de queratina no interior das lâminas epidérmicas. $O$ córion laminar apresentava dilatação dos vasos, edema e neutrófilos perivasculares.

Não foram encontradas alterações histológicas nos esôfagos dos Bovinos 6, 8 e 9, a não ser cistos de Sarcocystis sp nas fibras da camada de músculo esquelético. Os demais bovinos mostravam vários graus de necrose epitelial e inflamação. Essas lesões eram mais pronunciadas no terço final do esôfago. De modo geral havia áreas focalmente extensas de perda total do epitélio expondo tecido de granulação infiltrado por neutrófilos e células mononucleares (Fig.12). Nas áreas com epitélio remanescente havia vacuolização e atrofia do epitélio com exocitose neutrofílica. Sobre o tecido de granulação observavam-se bactérias e fibrina. No Bovino 4 observaram-se ainda numerosos trombos em vasos da lâmina própria. No Bovino 5 havia uma úlcera focalmente extensa com tecido de granulação imaturo, contínua com áreas de epitélio delgado (reepitelização). Abaixo da área reepitelizada havia pequenas áreas com fibrina e tecido de granulação. Em todos os casos observavam-se cistos de Sarcocystis sp nas fibras da camada de músculo esquelético.

Úlceras focais ou focalmente extensas foram observadas na mucosa do abomaso dos Bovinos 1, 2 e 5 . No Bovino 2, a ulceração focalmente extensa invadia a submucosa e era associada a colônias bacterianas. Hiperemia difusa e moderada foi anotada na mucosa do abomaso do Bovino 3. Na região cranioventral dos pulmões dos Bovinos 1 e 6 havia fibras vegetais nos bronquíolos, congestão moderada dos septos alveolares, edema e discreto infiltrado inflamatório misto. A presença de fibras no pulmão foi interpretada como um evento terminal ou mesmo um artefato de ocorrência pós-mortal. No rim do Bovino 4 havia grande quantidade de cilindros hialinos e granulosos no interior dos túbulos da cortical e medular. Vários desses túbulos estavam degenerados e alguns poucos apresentam regeneração do epitélio e infiltrado linfoplasmocitário multifocal na junção córtico-medular.

Hifema e hipópion foram observados respectivamente nos globos oculares do Bovino 2 e 9. Lesões no encéfalo ocorreram em seis novilhos (Bov.1-3, 5-7). Em todos os seis casos a lesão era focal, simétrica, restrita ao bulbo, na altura do óbex, e afetava a substância branca dorsolateral à área postrema e partes do núcleo dorsal do vago e do núcleo do nervo hipoglosso. A lesão consistia de rarefação desses núcleos por degeneração neuronal e edema. Em 4 desses casos (Bov.1, 2, 5 e 6) havia substituição da neurópila por agregados de células Gitter (Fig.13). No encéfalo dos Bovinos 4, 8 e 9 não foram encontradas alterações histológicas.

\section{DISCUSSÃO}

O diagnóstico de intoxicação por Ramaria flavo-brunnescens nos bovinos das Propriedades A e B baseou-se em dados epidemiológicos (época do ano e acesso irrestrito dos bovinos a bosques de eucalipto que continham grande quantidade do cogumelo), clínicos (principalmente salivação excessiva, afrouxamento e perda dos pêlos longos da cauda, alisamento da superfície dorsal da língua com ocasional ulceração, afrouxamento do estojo córneo dos chifres, hipópion, hifema e opacidade da córnea) e patológicos (confirmação das lesões orais e tegumentares e esofagite fibrinonecrótica). Esses dados são bastante característicos da intoxicação por $R$. flavo-brunnescens em bovinos (Bauer et al. 1966, Freitas et al. 1966, Quinõnes-Sowerby 1973, Santos et al. 1975, Paschoal et al. 1983, Zurbriggen et al. 1985, Kommers \& Santos 1995). As taxas de morbidade, mortalidade e letalidade foram respectivamente 50, 25 e 50\% na Propriedade A e 4,4, 2,5 e 67,1\% na Propriedade B o que é esperado para a toxicose.

É reconhecido que a toxidez do cogumelo $R$. flavo-brunnescens pode variar de ano a ano (Sallis et al. 2000, Sallis et al. 2004) e tem sido relatado que a intoxicação é comum após verões com estiagem seguidos de fortes chuvas (Paschoal et al. 1983, Zurbriggen et al. 1985, Tokarnia et al 2000). Nos surtos da doença aqui relatados observou-se que a quantidade de $R$. flavobrunnescens nos bosques de eucalipto era maior que nos 3-4 anos que antecederam os surtos e que a ocorrência da doença coincidiu com um período de fortes chuvas no outono que se seguiram a acentuada estiagem no verão.

Os achados hematológicos encontrados em dois novilhos deste estudo não são específicos, mas indicam inflamação subaguda. Sinais indicativos de inflamação aguda em bovinos incluem aumento na quantidade de neutrófilos segmentados (neutrofilia), que leva à inversão da relação linfócitos:neutrófilos, e aumento no número de bastonetes e/ou células precursoras menos diferenciadas, como metamielócitos e mielócitos (desvio à esquerda regenerativo). Essas alterações são freqüientemente observadas em diferentes doenças inflamatórias de caráter agudo e se mantêm por alguns dias, dependendo do agente etiológico e do tipo de injúria. Inflamações crônicas caracterizam-se por aumento na quantidade de monócitos e, em alguns casos, por linfocitose, principalmente quando resulta da infecção por microorganismos que causam estimulação antigênica persistente. Inflamações subagudas, como as observadas nos bovinos destes surtos, são vistas hematologicamente como desvio à esquerda associado ou não a monocitose (Kramer 2000).

As lesões de malacia focal simétrica encontradas no bulbo de 6 dos 9 novilhos necropsiados não tinham ainda sido relatadas em associação com a toxicose por R. flavo-brunnescens; em um relato (Freitas et al. 1966) degeneração neuronal e cromatólise 
são descritas no tronco encefálico de bovinos afetados pela toxicose, mas malacia focal não é mencionada. Embora não seja possível afirmar de forma definitiva que as lesões de malacia focal simétrica encontradas em nossos casos foram causadas pela(s) toxina(s) presentes no cogumelo, é improvável que a alta percentagem $(66,6 \%)$ dos bovinos necropsiados com a lesão seja apenas coincidência. Além disso, durante o exame rotineiro de 3.378 encéfalos de bovinos, utilizando a mesma metodologia, na rotina do LPV/UFSM durante os últimos 4 anos, nenhuma lesão semelhante foi observada nessa localização anatômica. Embora não se tenha observado nenhum sinal clínico de distúrbio nervoso associado a essas lesões nos bovinos desse relato, deve ser considerado que o exame clínico desses animais foi bastante superficial. Retrospectivamente, é possível inferir que o alto índice de miíases na comissura labial seja reflexo de déficits de nervos cranianos (por ex., nervo hipoglosso) que impediam o animal lamber os ferimentos nessa região. Sinais clínicos neurológicos como ataxia, tremores musculares e convulsões são relatados em ovinos em que os sinais clínicos eram associados a congestão e hemorragias perivasculares, principalmente nos colículos mesencefálicos e no cerebelo (Sallis et al. 2000). Congestão, edema, tumefação endotelial e hemorragia perivascular são estágios iniciais na malacia focal simétrica que ocorre em suínos intoxicados com sementes de Aeschynomene indica (Oliveira et al. 2005). A susceptibilidade de determinados locais do sistema nervoso central para malacia é bastante conhecida (Innes \& Saunders 1962) e focos de malacia simétricos ocorrem em animais, associados a outras intoxicações e toxinfecções. Essas incluem a ingestão de plantas do gênero Centaurea em eqüinos (Cordy 1978), doença do edema de suínos (Kurtz et al. 1969), toxifenção pela toxina de $C$. perfringens tipo $\mathrm{D}$ em ovinos (Buxton et al. 1978) e intoxicação por selênio em suínos (Harrison et al. 1983, Casteel et al. 1985). Essas semelhanças sugerem uma natureza vascular para as lesões do encéfalo dos novilhos deste estudo.

As lesões causadas pela(s) toxina(s) de $R$. flavo-brunnescens em ovinos foram atribuídas à isquemia resultante do espessamento da musculatura (miopaquinse) e degeneração do endotélio de arteríolas (Sallis et al. 2000), algo semelhante ao que é descrito no ergotismo (Coppock et al. 1989). À miopaquinse seguir-se-ia degeneração, necrose e ulceração dos epitélios (Sallis et al. 2000). Em nenhum dos nove novilhos deste relato se observaram lesões vasculares semelhantes às descritas em associação ao ergotismo (Coppock et al. 1989) e ou à intoxicação por R. flavo-brunnescens em ovinos (Sallis et al. 2000). A patogênese das lesões encontradas nos novilhos deste relato parece se enquadrar mais ao que já foi descrito para bovinos (Kommers \& Santos 1995). Esses últimos autores demonstraram que as alterações histopatológicas são mais acentuadas onde ocorre o processo de queratinização dura, onde há uma alta percentagem de aminoácidos ricos em enxofre, como a cistina, envolvidos no processo de queratinização; é sugerido que na intoxicação por $R$. flavo-brunnescens ocorra um distúrbio do metabolismo de proteínas com alto teor de enxofre, presentes nos queratinócitos. Isso resultaria na perda da estabilidade nas ligações moleculares da queratina dura e, conseqüentemente, no afrouxamento dos cascos, pêlos e chifres e na atrofia das papilas linguais. Essa hipótese parece bastante plausível quando se consi- dera que as lesões tegumentares encontradas em bovinos intoxicados por R. flavo-brunnescens são semelhantes às da intoxicação crônica por selênio em bovinos (O’ Toole \& Raibek 1995). Na intoxicação crônica por selênio, conhecida também como alkali disease, é proposto que, devido à semelhança entre os elementos selênio e enxofre, ocorra a substituição do enxofre pelo selênio nos resíduos de cisteína (que formariam uma molécula de cistina) das proteínas com alto teor de enxofre, levando a um afrouxamento das ligações cruzadas das pontes dissulfeto (O’Toole D. \& Raibek 1995). A semelhança morfológica entre a intoxicação por $R$. flavobrunnescens e a alkali disease explica o fato do mal do eucalipto ter sido inicialmente atribuído à intoxicação por selênio (Barros 1958).

A intoxicação por $R$. flavo-brunnescens em bovinos tem sido confundida com a febre aftosa (FA) devido a sialorréia e lesões da língua, semelhantes nas duas doenças (Bauer et al. 1966, Freitas et al. 1966, Zurbriggen et al. 1985, Rech et al. 2005). O diagnóstico diferencial com a FA é particularmente importante e não apresenta grandes dificuldades. A intoxicação por $R$. flavobrunnescens está sempre associada ao acesso dos bovinos a bosques de eucalipto no período de outono, não está associada à formação de vesículas na língua (presentes na FA), causa alisamento da superfície dorsal da língua por atrofia das papilas filiformes (lesão ausente na FA) e apresenta taxas de morbidade mais baixas e de mortalidade mais altas que a FA, embora alguns relatos da intoxicação por $R$. flavo-brunnescens indiquem uma morbidade de $90 \%$ (Freitas et al. 1966).

\section{REFERÊNCIAS}

Barros S.S. 1958. Da possível incidência da toxicose pelo selênio em bovinos no Rio Grande do Sul. Dipan, Porto Alegre, 11:10-13.

Bauer A.G., Laranja R.J. \& Santos A.G. 1966. Sobre a etiologia do chamado "Mal do Eucalipto". Arqs Inst. Vet. Desidério Finamor, Porto Alegre, 3:85-90.

Buxton D., Linklater K.A. \& Dyson D.A. 1978. Pulpy kidney disease and its diagnosis by histological examination. Vet. Rec. 102:241.

Casteel S.W., Osweiler G.D., Cook W.O., Daniels G. \& Kadlec R. 1985. Selenium toxicosis in swine. J. Am. Vet. Med. Assoc. 186:1084-1085.

Coppock E.W., Mostrom M.S., Simon J., McKenna D.J., Jacobsen B. \& Szlachta H.L. 1989. Cutaneous ergotism in a herd of dairy calves. J. Am. Vet. Med. Assoc. 194:549-551.

Cordy D.R. 1978. Centaurea species and equine nigropallidal encephalomalacia, p.327-336. In: Keeler R.F., Van Kampen K.R. \& James L.F. (ed.) Effects of Poisonous Plants on Livestock. Academic Press, New York. 600p.

Fidalgo O. \& Fidalgo M.E.P.K. 1970. A poisonous Ramaria from southern Brazil. Rickia 5:71-91.

Freitas J., Pasturino C.L., Quiñones-Sowerby C.A., Bellagamba C., Giambruno E., Infantozzi J.M., Decia J.C. \& Cervenanzky W. 1966. Comunicacion sobre uma enfermedad aparecida em ganados del Uruguay em los últimos anos (Bocopa). $5^{\circ}$ Congr. Panamericano Med. Vet. y Zootecnia, Caracas, p.152-159.

Harrison L.H., Colvin B.M., Stuart B.P., Sangster L.T, Gorgacz E.J. \& Gosser H.S. 1983. Paralysis in swine due to focal symmetrical poliomalacia: possible selenium toxicosis. Vet. Pathol. 20:265-273.

Innes J.R.M. \& Saunders L.Z. 1962. Encephalomalacia and myelomalacia, p.607-609. In: Ibid (ed.) Comparative Neuropathology. Academic Press, New York. 839p.

Kommers G.D. \& Santos M.N. 1995. Experimental poisoning of cattle by the mushroom Ramaria flavo-brunnescens (Clavariaceae): A study of the morphology and pathogenesis of lesions in the hooves, tail, horns and tongue. Vet. Human Toxicol. 37:297-302. 
Kramer J.W. 2000. Normal hematology in cattle, sheep and goat, p.10751084. In: Feldman B.F., Zinkl J.G. \& Jain N.C. (ed.) Schalm's Veterinary Hematology. 5th ed. Lippincott Williams \& Wilkins, Philadelphia. 1344p.

Kurtz H.J., Bergeland M.E. \& Barnes D.M. 1969. Pathologic changes in edema disease of swine. Am. J. Vet. Res. 30:791-806.

O'Toole D. \& Raibek M.S. 1995. Pathology of experimentally induced chronic selenosis (alkali disease) in yearling cattle. J. Vet. Diagn. Invest. 7:364-373.

Oliveira F.N., Rech R.R., Rissi D.R., Barros R.R. \& Barros C.S.L. 2005. Intoxicação em suínos pela ingestão de sementes de Aeschynomene indica (Leg.Papilionoideae). Pesq. Vet. Bras. 25:135-142.

Paschoal J.P., Portugal M.A.S.C. \& Nazario W. 1983. Ocorrência do "mal do eucalipto" em bovinos no estado de São Paulo. Arqs Inst. Biológico, São Paulo, 49:15-18.

Prucoli O. \& Camargo W.V.A. 1965/66. Intoxicação experimental em ovinos com Clavaria spp. Bolm Ind. Animal, Nova Odessa, 23:177-178.

Quinõnes-Sowerby C.A. 1973. Bocopa. Bolsa del Livro de la Facultad de Veterinaria, Montevideo, p.1-13.

Rech R.R., Schild A.L., Driemeier D., Garmatz S.L., Oliveira F.N., Riet-Correa F. \& Barros C.S.L. 2005. Febre catarral maligna em bovinos no Rio Grande do Sul: epidemiologia, sinais clínicos e patologia. Pesq. Vet. Bras. 25:97105.

Riet-Correa F., Barros C.S.L. \& Schild A.L. 2004. Intoxication by Ramaria flavo-brunnescens in domestic animals, p.488-493. In: Acamovic T., Stewart C.S. \& Pennycott T.W. (ed.) Poisonous Plants and Related Toxins. CAB International, Londres. 586p.

Riet-Correa F., Schild A.L., Méndez M.C., Oliveira J.A., Gil Turnes C. \& Gonçalves A. 1983. Relatório de Atividade e Doenças da Área de Influência do
Laboratório Regional de Diagnóstico no Período 1978/1982. UFPel, Pelotas, RS, p.54-55.

Rozza D.B., Spagnol C., Silva E.B., Callado A.C.C., Oliveira E.C. \& Driemeier D. 2004. Intoxicação por Ramaria flavo-brunnescens em búfalos. Pesq. Vet. Bras. 24(Supl.):56-57.

Sallis E.S.V., Raffi M.B. \& Riet-Correa F. 2004. Intoxicação experimental em ovinos com Ramaria flavo-brunnescens congelada ou dessecada. Pesq. Vet. Bras. 24:107-110.

Sallis E.S.V., Riet-Correa F., Raffi M.B. \& Méndez M.C. 2000. Experimental intoxication by the mushroom Ramaria flavo-brunnescens in sheep. Vet. Human Toxicol. 42:321-324.

Santos M.N. 1993. Intoxicação por Ramaria flavo-brunnescens, p.309-318. In: Riet-Correa F., Méndez M.C. \& Schild A.L. (ed.) Intoxicações por Plantas e Micotoxicoses em Animais Domésticos. Editorial Agropecuária Hemisfério Sul do Brasil, Pelotas. 340p.

Santos M.N., Barros S.S. \& Barros C.S.L. 1975. Intoxicação em bovinos pelo cogumelo Ramaria flavo-brunnescens. Pesq. Agropec. Bras., Sér. Vet. 10:105109.

Stöber M. 1990. Identificação, anamnese, regras básicas da técnica de exame clínico geral, p.44-80. In: Dirksen G., Gründner H.-D. \& Stöber M. (ed.) Rosenberger Exame Clínico dos Bovinos. $3^{\mathrm{a}}$ ed. Guanabara-Koogan, Rio de Janeiro. 418p.

Tokarnia C.H., Döbereiner J. \& Peixoto P.V. 2000. Plantas Tóxicas do Brasil, p.206-209. Editora Helianthus, Rio de Janeiro. 310p.

Zurbriggen M.A., Homse A.C., Rochinotti D., Somma de Fere G.R., Draghi de Benitez M.G., Báez Kohn A.R., Vanzini V.R. \& Soni C.A. 1985. Mal des los eucaliptales. Vet. Argent. 12:273-281. 